\title{
ESTABILIDADE OXIDATIVA DOS ÓLEOS DE MACADÂMIA E DE PISTACHE*
}

\author{
DENISE DE F. S. DE SOUZA** \\ ROSEMAR ANTONIASSI*** \\ SIDINÉA CORDEIRO DE FREITAS**** \\ HUMBERTO RIBEIRO BIZZO*****
}

\begin{abstract}
O objetivo deste trabalho foi a avaliação da composição e da estabilidade oxidativa dos óleos de macadâmia e de pistache. Os óleos de amostras de amêndoas de macadâmia e pistache foram analisados quanto à composição em ácidos graxos, triacilgliceróis e esteróis. A estabilidade oxidativa (OSI) foi avaliada em Rancimat 679 Metrohm nas temperaturas de 98,110 e $120^{\circ} \mathrm{C}$ com fluxos de ar de 8,33 e $10 \mathrm{~L} / \mathrm{h}$. Os óleos de macadâmia e de pistache foram também adicionados aos óleos de soja e de girassol (em níveis de 5 a 20\%) para se avaliar possível aumento de estabilidade oxidativa desses últimos. As amostras de óleo de macadâmia apresentaram como ácidos graxos predominantes 0 oléico $(63,41$ a $67,03 \%)$ e o palmitoléico $(10,32$ a $14,27 \%)$, enquanto que no óleo de pistache predominaram o oléico $(53,83$ a $56,85 \%)$ e linoléico (31,38 a 32,26\%). O índice de estabilidade oxidativa (OSI) a $98^{\circ} \mathrm{C}$ para os óleos de pistache e macadâmia atingiram, respectivamente, 93h e valores maiores que $96 \mathrm{~h}$, indicativos de alta estabilidade oxidativa. Tais valores encontram-se entre os mais altos relatados na literatura para óleos vegetais nessa temperatura. Ocorreu redução do OSI com o aumento de temperatura, tanto para o óleo de macadâmia como para o de pistache. Verificou-se apenas discreto aumento na estabilidade oxidativa das misturas de óleos de soja e girassol após a adição dos óleos de pistache e macadâmia.
\end{abstract}

PALAVRAS-CHAVE: MACADÂMIA; PISTACHE; ÓLEO; ÍNDICE DE ESTABILIDADE OXIDATIVA; RANCIMAT.

* Parte da tese de mestrado do primeiro autor.

** Nutricionista, Mestranda, Universidade Federal Rural do Rio de Janeiro (UFRRJ - IT/DTA), Seropédica RJ, Brasil (e-mail: dfssouza@click21.com.br) .

*** Engenheira de Alimentos, doutora em Engenharia de Alimentos, pesquisadora da EMBRAPA Agroindústria de Alimentos, Rio de Janeiro, RJ (e-mail: rosemar@ctaa.embrapa.br).

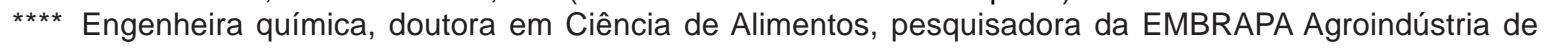
Alimentos (e-mail: sidi@ctaa.embrapa.br).

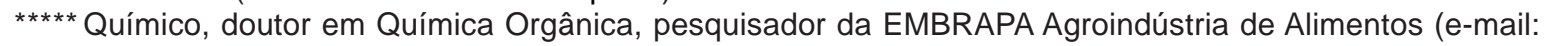
bizzo@ctaa.embrapa.br). 


\section{INTRODUÇÃO}

As amêndoas de macadâmia e pistache apresentam altos teores de óleo de reconhecida qualidade (considerados como "gourmet oils"), podendo alcançar preços elevados no mercado pela pequena oferta e usos diversos.

A nogueira macadâmia (Macadamia integrifolia Maiden \& Betche), árvore da família Proteaceae, é originária da Austrália e foi introduzida no Havaí em 1878. No Brasil foi introduzida em 1931, mas sua expansão ocorreu a partir da década de 80 nos Estados de São Paulo, Bahia, Espírito Santo, Rio de Janeiro e Minas Gerais (SACRAMENTO e PEREIRA, 2003).

Embora o Brasil apresente condições edafoclimáticas favoráveis à cultura de macadâmia, seu cultivo ainda é pouco expressivo. Os estados de São Paulo, Bahia e Espírito Santo suportam mais de $90 \%$ da produção estando o restante distribuído nos estados de Minas Gerias, Rio de Janeiro e Goiás (PAULINO e MARCHINI, 1998).

A produção mundial de macadâmia, liderada pela Austrália e Estados Unidos, foi de 92 mil toneladas na safra 2003/2004 (USDA, 2007).

Estudos recentes realizados por ALLMAN-FARINELLI et al. (2005) e BINKOSKI et al. (2005) confirmam que dietas com óleos ricos em ácidos graxos monoinsaturados alteram favoravelmente o perfil lipídico, com redução no colesterol total, LDL colesterol e triacilgliceróis.

GARG, BRAKE e WILLS (2003) conduziram experimento com 17 pacientes de hipercolesterolemia por 4 semanas, incluindo o consumo de 40 a $90 \mathrm{~g} /$ dia de macadâmia (equivalente a $15 \%$ do total de energia consumida). Verificaram decréscimo no colesterol total e LDL colesterol com aumento de HDL-colesterol, enquanto os níveis de triacilgliceróis e de homocisteína não foram afetados pela dieta. Numa revisão dos trabalhos sobre o assunto, MUKUDDEM-PETERSEN, OOSTHUIZEN e JERLING (2005), discutiram a associação inversa entre o consumo de amêndoas e os fatores marcadores de risco para doenças cardiovasculares. Constataram que o consumo das mesmas altera o perfil lipídico de humanos, reduzindo o colesterol total e o LDL - colesterol. Sugeriram que o consumo de amêndoas (50-100 g/dia e 5 vezes por semana) como parte de dieta saudável para o coração pode reduzir significativamente o colesterol em indivíduos com hiperlipidemias.

O pistache é cultivado principalmente no Irã, Estados Unidos, Turquia e Síria com produção em torno de 476 mil toneladas em 2005 (FAO, 2007). Não existem dados disponíveis sobre a estabilidade oxidativa desse óleo, enquanto que alguns resultados relativos à sua composição são conflitantes conforme reportado por ASLAN, ORHAN e SENER (2002) e YILDIZ, GURCAN e OZDEMIR (1998).

A estabilidade oxidativa constitui parâmetro global para avaliação da qualidade de óleos e gorduras que não depende apenas da sua composição química e da qualidade da matéria-prima. Reflete também as condições a que foi submetido durante o processamento e armazenamento até o momento em que se realiza a determinação do período de indução (HILL, 1994; ROSALES, 1989).

Para se verificar a estabilidade dos óleos ou sua suscetibilidade à oxidação, a amostra é submetida ao teste de oxidação acelerada, sob condições padronizadas, pela elevação de temperatura, adição de metais, aumento da pressão de oxigênio, estocagem sob luz e agitação. No entanto, o aquecimento é o meio mais utilizado e mais eficiente para acelerar a oxidação (ANTONIASSI, 2001).

A partir dos resultados verificados pelos métodos de estabilidade oxidativa obtém-se como parâmetro o período de indução, ou índice de estabilidade oxidativa, que é definido como o tempo necessário para que os óleos atinjam nível de rancidez detectável ou surpreendente mudança na taxa de oxidação (FRANKEL, 1993; HILL, 1994; ROSALES, 1989; LAUBLI e BRUTTEL, 1986). 
O presente trabalho teve por objetivo avaliar a composição e a estabilidade oxidativa dos óleos de macadâmia e pistache, sob diferentes condições. A macadâmia é uma amêndoa com plantação comercial no Brasil, cujo excedente de produção poderia ser utilizado para produção de óleo, diversificando seu mercado. Os óleos "gourmet" apresentam potencial de expansão de mercado principalmente no exterior. As poucas informações disponíveis sobre os óleos de macadâmia e de pistache justificam o presente trabalho.

\section{MATERIAL E MÉTODOS}

\subsection{MATERIAL}

As amostras de macadâmia crua e não-salgada (codificadas como M4), embaladas a vácuo em saco de alumínio multicamadas, foram fornecidas pela Fazenda SIMAB, Piraí, Rio de Janeiro.

As amostras de amêndoas de macadâmia crua e salgada (codificadas como M1), as amêndoas de macadâmia não-salgada e frita (M5), as amostras de pistache salgadas e os óleos de soja e girassol refinados e desodorizados foram obtidos no comércio da Cidade do Rio de Janeiro.

\subsection{MÉTODOS}

As amostras foram analisadas no momento do recebimento e durante armazenamento de 6 meses, sob temperatura de $-18^{\circ} \mathrm{C}$.

As amêndoas foram trituradas em blender, seguindo-se a extração do óleo com éter de petróleo $\left(30-60^{\circ} \mathrm{C}\right)$ durante $16 \mathrm{~h}$ em extrator Soxhlet.

Os ésteres metílicos foram preparados de acordo com HARTMAN e LAGO (1973) e analisados por cromatografia a gás de alta resolução, em aparelho HP 5890, equipado com detector de ionização de chama operado a $280^{\circ} \mathrm{C}$. Utilizou-se coluna capilar de sílica fundida de filme de cianopropilssiloxano $(60 \mathrm{~m} \times 0,32 \mathrm{~mm} \times 0,25 \mu \mathrm{m})$, com programação de temperatura de $150^{\circ} \mathrm{C}$ a $200^{\circ} \mathrm{C}$ e $1,3^{\circ} \mathrm{C} / \mathrm{min}$. Foi injetado $1 \mu \mathrm{L}$ de amostra em injetor aquecido a $250^{\circ} \mathrm{C}$, operado no modo de divisão de fluxo de 1:50. Realizou-se a identificação por comparação dos tempos de retenção com os padrões da NUCHECK Inc. (Elysian, IL) e a quantificação por normalização interna.

Os teores de matéria insaponificável e de ácidos graxos livres, bem como o índice de peróxidos foram determinados de acordo com os métodos Ca 6b-53, Ca 5a-40 e Cd 8-53 da AOCS (1997), respectivamente.

A partir da matéria insaponificável, os esteróis foram isolados por cromatografia em camada delgada de acordo com o método 2.404 da IUPAC (1992) e analisados por cromatografia a gás em coluna capilar de sílica fundida de filme de OV - 17 (25 $\mathrm{m} \times 0,25 \mathrm{~mm} \times 0,25 \mu \mathrm{m})$, com programação de temperatura de $280^{\circ} \mathrm{C}$ a $305^{\circ} \mathrm{C}, 3^{\circ} \mathrm{C} /$ minuto. $\mathrm{O}$ detector de ionização de chama e o injetor foram mantidos a $300^{\circ} \mathrm{C}$. Foi injetado $1 \mu \mathrm{L}$ de amostra em injetor operado no modo de divisão de fluxo de 1:20. Os compostos foram identificados por co-injeção de padrões e a quantificação realizada por normalização interna.

Para análise do perfil de triacilgliceróis, o fracionamento da amostra ocorreu por extração em fase sólida de acordo com LERCKER et al. (1992). Numa coluna de vidro adicionaram-se $500 \mathrm{mg}$ de sílica 60 (Merck) e em seguida cerca de $1,0 \mathrm{~cm}$ de sulfato de sódio anidro p.a. $\mathrm{O}$ acondicionamento da coluna foi realizado mediante passagem pela coluna de $3 \mathrm{~mL}$ de hexano. Cerca de $20 \mathrm{mg}$ de gordura foram dissolvidas em hexano e carregadas no topo da coluna. Os triacilgliceróis foram eluídos com adição de $3 \mathrm{~mL}$ de hexano, seguida de $3 \mathrm{~mL}$ de solução hexano:éter etílico (8:2). Levou-se a solução eluída pela coluna à secura, a qual foi diluida em $10 \mathrm{~mL}$ de 
hexano com grau de pureza cromatográfica. A análise dos triacilgliceróis foi realizada em cromatógrafo a gás, Varian 3400 , equipado com injetor de temperatura programada (inicial $100^{\circ} \mathrm{C}$, isoterma de 0,25 minutos, e de 100 a $380^{\circ} \mathrm{C}$ na razão de $200^{\circ} \mathrm{C} /$ minuto). A injeção de $1 \mu \mathrm{L}$ de amostra foi realizada no modo sem divisão de fluxo. Utilizou-se coluna capilar de sílica fundida DB5HT ( $5 \%$ fenil - 95\% metilsilicone) de $30 \mathrm{~m} \times 0,32 \mathrm{~mm} \times 0,1 \mu \mathrm{m}$ com programação de temperatura (inicial de $210^{\circ} \mathrm{C}, 1$ minuto, de $210-250^{\circ} \mathrm{C} / 20^{\circ} \mathrm{C} /$ minuto, de $250-360^{\circ} \mathrm{C} / 4^{\circ} \mathrm{C} /$ minuto). O detector de ionização de chama foi operado a $400^{\circ} \mathrm{C}$. Os compostos foram identificados por co-injeção de padrões e a quantificação realizada por normalização interna.

O Índice de Estabilidade Oxidativa do óleo (Oil Stability Index-OSI) foi determinado no Rancimat 679 Methrom, a $97,8^{\circ} \mathrm{C}$ sob fluxo de ar de $8,33 \mathrm{~L} / \mathrm{h}$ e nas temperaturas de $110^{\circ}$ e $120^{\circ} \mathrm{C}$ sob fluxo de ar de $10 \mathrm{~L} / \mathrm{h}$, utilizando-se amostras de $5 \mathrm{~g}$ de óleo (AOCS, 1997).

Os óleos de macadâmia e de pistache foram adicionados aos óleos desodorizados de girassol e soja nos níveis de 5 a 20\% (v/v) e a estabilidade oxidativa (OSI) avaliada no Rancimat a $98^{\circ} \mathrm{C}$, com fluxo de ar de $8,33 \mathrm{~L} / \mathrm{h}$ e $5 \mathrm{~g}$ de amostra. Todas as análises foram realizadas em duplicata.

\section{RESULTADOS E DISCUSSÃO}

\subsection{COMPOSIÇÃO DAS AMÊNDOAS E DOS ÓLEOS DE MACADÂMIA E DE PISTACHE}

O teor de óleo de macadâmia das amostras analisadas variou de 74,19 a 79,77\% (Tabela 1). Tais resultados são semelhantes aos obtidos por MARROCOS et al. (1996) para variedades brasileiras e na faixa dos resultados de variedades da Nova Zelândia, reportados por KAIJSER, DUTTA e SAVAGE (2000). A amostra de macadâmia frita não apresentou teor de óleo superior às demais. A acidez situou-se abaixo dos resultados citados por MACFARLANE e HARRIS (1981) e OLIVEIRA et al. (1980). Tal fato indica baixo nível de hidrólise, que está diretamente relacionado com a umidade da amêndoa. O valor obtido para o teor de matéria insaponificável mostrou-se semelhante ao verificado por MACFARLANE e HARRIS (1981).

\section{TABELA 1 - COMPOSIÇÃO DAS AMÊNDOAS E DOS ÓLEOS DE MACADÂMIA E PISTACHE}

\begin{tabular}{lcc}
\hline Análise & Macadâmia & Pistache \\
\hline Teor de Óleo (\% base úmida) & $74,19-79,77$ & $46,09-50,95$ \\
Acidez do óleo (expressa em \% de ácido oléico) & $0,14-0,27$ & $0,34-0,68$ \\
Teor de Matéria insaponificável (\% do óleo) & $0,45-0,64$ & $1,17-1,39$ \\
\hline
\end{tabular}

Para as amostras de pistache os resultados variaram de 46,09 a 50,95\% de óleo (Tabela 1), compatíveis com a diferença encontrada para amostras verdes e maduras de variedades turcas e iranianas analisadas por ASLAN, ORHAN e SENER (2002).

O óleo de macadâmia apresentou teores de ácidos graxos insaturados de 82,35 a 83,61\% e de saturados de 16,22 a 16,91\%. Os ácidos graxos predominantes foram o oléico (63,41 a 67,30\%) e o palmitoléico (10,32 a 14,27\%), sendo o teor máximo de linoléico de 1,82\% e do ácido linolênico de $0,12 \%$ (Tabela 2 ). 


\begin{tabular}{|c|c|c|}
\hline Ácido G raxo & M a c a dâm ia & $P$ istache \\
\hline 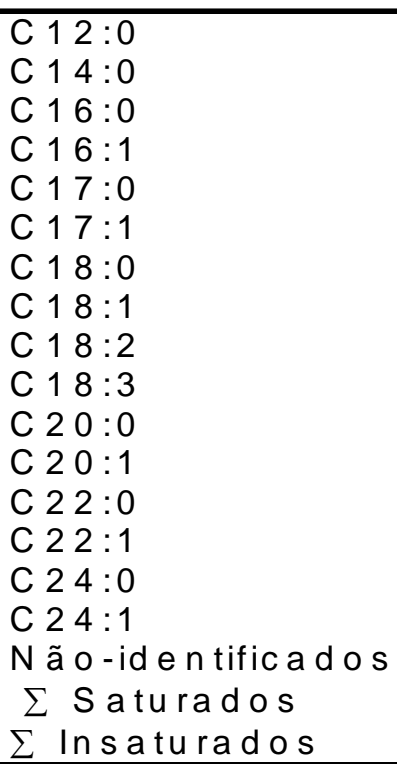 & $\begin{array}{c}\text { Tr }-0,07 \\
0,35-0,68 \\
5,66-7,05 \\
10,32-14,27 \\
\operatorname{Tr} \\
\operatorname{Tr} \\
3,38-4,43 \\
63,41-67,30 \\
1,57-1,82 \\
\operatorname{Tr}-0,12 \\
3,42-4,36 \\
2,95-3,62 \\
1,18-1,32 \\
0,33-0,39 \\
0,42-0,66 \\
- \\
\operatorname{Tr}-0,41 \\
16,22-16,91 \\
82,35-83,61\end{array}$ & $\begin{array}{c}\mathrm{Tr} \\
\operatorname{Tr}-0,09 \\
8,02-10,63 \\
0,72-1,12 \\
\operatorname{Tr} \\
\operatorname{Tr} \\
1,20-1,32 \\
53,83-56,85 \\
31,38-32,26 \\
0,55-0,57 \\
\operatorname{Tr}-0,20 \\
0,40-0,58 \\
\operatorname{Tr}-0,12 \\
\operatorname{Tr} \\
\operatorname{Tr} \\
\operatorname{Tr} \\
\operatorname{Tr}-0,22 \\
9,66-11,92 \\
88,08-90,11\end{array}$ \\
\hline
\end{tabular}

$\operatorname{Tr}=$ traços.

- = não-detectado.

O óleo de macadâmia apresentou característica bastante incomum. O teor de oléico aproximou-se do teor presente nos óleos de abacate e oliva, enquanto o alto teor de palmitoléico assemelhou-se ao do óleo de abacate. No entanto, os teores de linoléico e linolênico foram inferiores aos reportados para os óleos de abacate e oliva (CODEX ALIMENTARIUS, 2001; LOZANO et al., 2003). O óleo de macadâmia apresentou teores de C20:0, C20:1, C22:0, C22:1 e C24:0 superiores à maioria dos óleos vegetais, característica que poderá ser utilizada para diferenciar óleos adulterados. Os teores de palmitoléico e oléico ficaram abaixo dos resultados citados por MAGUIRE et al. (2004) e KAIJSER, DUTTA e SAVAGE (2000) para variedades da Nova Zelândia, ressaltando as diferenças da composição dos ácidos graxos entre as variedades da macadâmia.

Os teores de ácidos graxos insaturados do pistache variaram de 88,08 a 90,11\%, com predomínio de oléico $(53,83$ a 56,85\%) e linoléico (31,38 a 32,26\%), enquanto os saturados variaram de 9,66 a $11,92 \%$.

Os teores de monoinsaturados e saturados encontrados mostraram-se, de maneira geral, menores que os relatados pela literatura, sendo os teores de insaturados maiores. Tal diferença pode ser percebida também na análise de amostras verdes e maduras de variedades do Irã e Turquia realizada por ASLAN, ORHAN e SENER (2002).

A composição em triacilgliceróis para o óleo de pistache revelou apenas 4 classes principais (Tabela 3). Triacilgliceróis com 54 átomos de carbono englobam os ácidos graxos com 18 carbonos (principais componentes do óleo de pistache), enquanto que C52 refere-se aos triacilgliceróis que são compostos principalmente por dois ácidos graxos com 18 carbonos e um ácido graxo com 16 carbonos.

O óleo de macadâmia apresenta em sua composição, triacilgliceróis de C48 a C58 átomos de carbono, indicativos da presença de ácidos graxos com 16 carbonos (palmítico e palmitoléico) e 20, 22 e 24 carbonos. Nas condições utilizadas não há separação de triacilgliceróis por números 
de duplas ligações, mas os resultados encontrados são semelhantes aos obtidos por HOLCAPEK et al. (2003).

\section{TABELA 3 - COMPOSIÇÃO TRIACILGLICERÓLICA DE ÓLEOS DE MACADÂMIA E DE PISTACHE}

\begin{tabular}{ccccccc}
\hline \multirow{2}{*}{ Óleo } & \multicolumn{7}{c}{ Triacilglicerol (valores médios, em \%) } \\
& $\mathbf{C 4 8}$ & $\mathbf{C 5 0}$ & $\mathbf{C 5 2}$ & $\mathbf{C 5 4}$ & $\mathbf{C 5 6}$ & $\mathbf{C 5 8}$ \\
\hline Pistache & - & 5,02 & 33,67 & 60,29 & 1,03 & - \\
Macadâmia & 3,48 & 15,40 & 35,21 & 36,66 & 7,99 & 1,26 \\
\hline
\end{tabular}

- = não-detectado.

A análise dos esteróis da amostra de óleo de macadâmia revelou composição que pode servir como parâmetro para avaliação de adulteração, como ocorre com o azeite de oliva. Foi observado teor de $83,33 \%$ de $\beta$ sitosterol, $5,98 \%$ de campesterol, $8,42 \%$ de $\Delta^{5}$ avenasterol e $2,25 \%$ de $\Delta^{7}$ estigmastenol. Estigmasterol não foi detectado (Tabela 4).

Em geral, os óleos contém teores elevados de sitosterol que variam de 52 a 93\%. O campesterol varia numa faixa de 2 a $23 \%$ e o estigmasterol de 1 a 20\% (GUNSTONE, HARWOOD e PADLEY 1994).

Na composição de esteróis de óleo de macadâmia reportada por MAGUIRE et al. (2004), os teores de campesterol, estigmasterol e de $\beta$ sitosterol foram de 4,$5 ; 2,4$ e $93 \%$, sendo que provavelmente esse último resultado deve ser relativo também à co-eluição de $\beta$ sitosterol e $\Delta^{5}$ avenasterol.

\section{TABELA 4 - COMPOSIÇÃO EM ESTERÓIS DO ÓLEO DE MACADÂMIA E DE PISTACHE}

\section{Esteróis $\quad$ Macadâmia (\%) $\quad$ Pistache (\%)}

$\begin{array}{lcc}\text { Campesterol } & 5,98 & 4,21 \\ \text { Estigmasterol } & - & 0,24 \\ \beta \text { Sitosterol } & 83,33 & 85,13 \\ \triangle^{5} \text { Avenasterol } & 8,42 & 9,02 \\ \Delta^{7} \text { Estigmastenol } & 2,25 & - \\ \text { Não-identificados } & 0,02 & 1,40\end{array}$

- = não-detectado.

O óleo de pistache apresentou composição em esteróis próxima a da macadâmia, exceto pela ausência de $\Delta^{7}$ estigmastenol (Tabela 4). DANECHRAD (1974) relatou valores de $85 \%$ de sitosterol, $11 \%$ de $\Delta^{7}$ estigmastenol e $4 \%$ de campesterol. Para variedades turcas de pistache, 
YILDIZ, GURCAN e OZDEMIR (1998) encontraram valores de $\beta$ sitosterol variando de 82 a $89 \%, \Delta^{5}$ avenasterol de 0,8 a 2,4\% e estigmasterol de 5,3 a 7,3\%, enquanto o nível máximo de campesterol foi de 1,2\%. Essa inversão entre valores de campesterol e estigmasterol é incomum na natureza, mas os autores não comentaram a ocorrência. Como a composição em esteróis constitui característica de cada planta, as variações enquadram-se em faixas limitadas. Dependendo das condições da análise e das colunas utilizadas pode ocorrer co-eluição de esteróis. Entretanto, mesmo variando-se a polaridade da coluna não ocorreria inversão de eluição entre campesterol e estigmasterol.

\subsection{ESTABILIDADE OXIDATIVA DOS ÓLEOS DE MACADÂMIA E DE PISTACHE}

O índice de estabilidade oxidativa (OSI) dos óleos de macadâmia e de pistache foi avaliado a 98,110 e $120^{\circ} \mathrm{C}$. Para os casos em que não houve aumento na taxa de oxidação após 96 horas de análise, o equipamento foi desligado e o valor de OSI reportado como maior que 96 horas (Tabela 5).

A amostra de amêndoa de macadâmia crua e salgada (M1) foi analisada e armazenada em freezer por até 5 meses. Os óleos obtidos das amêndoas de macadâmia no tempo zero e das amêndoas armazenadas em freezer por 4 meses apresentaram OSI maior que 96 horas. Para a amêndoa que foi armazenada por 5 meses verificou-se redução de OSI para 79,6 horas, indicando redução na estabilidade oxidativa a partir do $5^{\circ}$ mês de congelamento.

KAIJSER, DUTTA e SAVAGE (2000) relataram que para maior estabilidade das amêndoas de macadâmia, a umidade deveria estar abaixo de $1 \%$ e o armazenamento ocorrer abaixo de $-18{ }^{\circ} \mathrm{C}$. Os resultados indicaram que mesmo com o congelamento ocorreria perda de estabilidade oxidativa do óleo após 5 meses de armazenamento das amêndoas.

\section{TABELA 5 - ESTABILIDADE OXIDATIVA DAS AMOSTRAS DE ÓLEO DE MACADÂMIA}

\begin{tabular}{|c|c|c|c|c|c|}
\hline \multirow[t]{2}{*}{ Amostra } & \multirow{2}{*}{$\begin{array}{c}\text { Tempo de } \\
\text { armazenamento } \\
\text { (meses) }\end{array}$} & \multirow{2}{*}{$\begin{array}{l}\text { Índice de } \\
\text { Peróxido } \\
\text { (meq/kg) }\end{array}$} & \multicolumn{3}{|c|}{$\begin{array}{c}\text { Índice de Estabilidade Oxidativa } \\
\text { (h) }\end{array}$} \\
\hline & & & $98^{\circ} \mathrm{C}^{2}$ & $110^{\circ} \mathrm{C}^{3}$ & $120^{\circ} \mathrm{C}^{3}$ \\
\hline $\begin{array}{l}\text { Amêndoa crua e salgada } \\
\text { (M1) }\end{array}$ & Inicial & nd & $>96,0$ & nd & nd \\
\hline $\begin{array}{l}\text { Amêndoa crua e salgada } \\
\text { (M1) }\end{array}$ & 4 & 0 & $>96,0$ & 37,4 & 16,1 \\
\hline $\begin{array}{l}\text { Óleo da amêndoa crua e } \\
\text { salgada }\left(M 1^{1}\right)\end{array}$ & 4 & 1,32 & 70,0 & 28,0 & 11,8 \\
\hline $\begin{array}{l}\text { Amêndoa crua e salgada } \\
\text { (M1) }\end{array}$ & 5 & 0,64 & 79,6 & 24,3 & 15,6 \\
\hline $\begin{array}{l}\text { Amêndoa crua e não- } \\
\text { salgada (M4) }\end{array}$ & Inicial & 1,95 & 88,6 & 22,9 & 14,6 \\
\hline $\begin{array}{l}\text { Amêndoa frita e não- } \\
\text { salgada (M 5) }\end{array}$ & Inicial & 2,75 & 40,3 & 13,7 & 5,6 \\
\hline
\end{tabular}

M1 = óleo de macadâmia crua e salgada, extraído após os tempos de armazenamento das amêndoas de 0,4 e 5 meses.

M4 = óleo de macadâmia crua e não-salgada.

M5 = óleo de macadâmia não-salgada e frita.

1 resultados obtidos após 4 meses de conservação do óleo em freezer.

2 fluxo de ar de 8,33 L/h.

3 fluxo de ar de $10 \mathrm{~L} / \mathrm{h}$.

nd = não-determinado. 
O óleo obtido da amostra M1, armazenado em freezer por 4 meses, apresentou valor de OSI de 70 horas (Rancimat a $98^{\circ} \mathrm{C}$ ). Verificou-se maior estabilidade oxidativa para a amostra congelada da amêndoa, indicando que o óleo estaria mais protegido na amêndoa e que ocorreria redução de estabilidade do óleo mesmo sob congelamento.

O óleo da amêndoa não-salgada e frita (M5) apresentou estabilidade de 40,3 horas a $98^{\circ} \mathrm{C}$, provavelmente devido ao processo de fritura (em condições de tempo e temperatura desconhecidas).

Para MASON e MCCONACHIE (1994), a qualidade das amêndoas fritas poderia ser melhorada pela redução de temperatura e pela utilização do próprio óleo de macadâmia no processo de frituras.

O óleo da amêndoa crua não-salgada (M4) apresentou OSI de 88,6 horas a $98^{\circ} \mathrm{C}$, inferior à amostra de amêndoa crua e salgada devido provavelmente a diferenças de tempo e processamento.

Os valores de OSI superiores a 96h, obtidos para os óleos de macadâmia, encontram-se entre os mais altos já relatados na literatura para óleos vegetais (rancimat $-98^{\circ} \mathrm{C}$ ). Para o azeite de oliva, LÄUBLI e BRUTTEL (1986) obtiveram OSI de $29,3 \mathrm{~h}$, a $100^{\circ} \mathrm{C}$ e fluxo de ar de $10 \mathrm{~L} / \mathrm{h}$. ROSALES (1989) encontrou variação de 6,7 a 79,8h, analisando 26 amostras de azeite de oliva a temperatura de $100^{\circ} \mathrm{C}$. Para o óleo de abacate, ANTONIASSI, PEÇANHA e LAGO (1998) relataram OSI maior que $48 \mathrm{~h}$ tanto a 98 como a $110^{\circ} \mathrm{C}$ e fluxo de ar de $8,33 \mathrm{~L} / \mathrm{h}$ e $10 \mathrm{~L} / \mathrm{h}$, respectivamente.

Maiores valores de OSI indicam maior estabilidade do óleo nas condições analisadas. Entretanto, as comparações são dificultadas pelas diferenças entre condições de análise como temperatura, fluxo de ar e quantidade de óleo.

A alta estabilidade oxidativa está associada com a composição em ácidos graxos, que no caso do óleo de macadâmia é bastante favorável em função dos altos teores de ácidos graxos monoinsaturados e baixo em polinsaturados (C18:2 e C18:3) (Tabela 2). Baixos níveis de peróxidos e de acidez também contribuiriam para a maior estabilidade oxidativa (Tabelas 1 e 5).

Os teores de matéria insaponificável obtidos para o óleo de macadâmia (Tabela 1) variaram de 0,45 a 0,64\%, que são baixos quando comparados com óleo de abacate (LOZANO et al., 1993).

A alta estabilidade do óleo de macadâmia não pode ser atribuída ao teor de tocoferol (4,8 ppm de $\Delta$ tocoferol e $48 \mathrm{ppm}$ de $\alpha$ tocotrienol para as amêndoas) citado por KAIJSER, DUTTA e SAVAGE (2000), mas possivelmente à presença de compostos fenólicos identificados por QUINN e TANG (1996) no óleo da amêndoa e nas cascas que as envolvem.

Os índices de estabilidade oxidativa sofreram redução com o aumento da temperatura, que na análise a $110^{\circ} \mathrm{C}$ variaram de 13,7 a $37 \mathrm{~h}$ e a $120^{\circ} \mathrm{C}$ de 5,6 a $16,1 \mathrm{~h}$ com fluxo de ar de $10 \mathrm{~L} / \mathrm{h}$.

O índice de estabilidade oxidativa para o óleo de macadâmia (Rancimat, $130^{\circ} \mathrm{C}$ e fluxo de ar de 20 L/h) foi relatado por QUINN e TANG (1996) como 9,2h e 8,7h para óleos obtidos por prensagem de amêndoas de macadâmia (cultivar Keauhou, de Macadamia integrifolia) com casca e sem casca, respectivamente. Para os óleos bruto e refinado comerciais foram obtidos valores de OSI de 5,5 e 0,5h, respectivamente, que indicam perda de antioxidantes naturais durante o refino.

KAIJSER, DUTTA e SAVAGE (2000) encontraram valores de OSI no Rancimat a $120^{\circ} \mathrm{C}$ (fluxo de ar não-relatado) de 3,6 a 19,75h quando analisaram óleos de algumas variedades de macadâmia. Afirmaram que não havia correlação clara entre os resultados, a composição em ácidos graxos e os teores de tocoferóis e de $\Delta^{5}$ avenasterol, ao qual tem sido atribuída atividade antioxidante.

Os valores de OSI obtidos para o óleo de pistache (Tabela 6) também foram bastante elevados, variando de 56,5 a 93 horas (Rancimat $98^{\circ} \mathrm{C}$ e $8,33 \mathrm{~L} / \mathrm{h}$ ). Verificou-se redução do OSI para o óleo de pistache obtido da amêndoa armazenada por 3 meses, indicando que mesmo sob congelamento ocorreu perda de estabilidade.

Nas temperaturas de 110 e $120^{\circ} \mathrm{C}$, as amostras de óleo de pistache apresentaram redução da estabilidade oxidativa proporcionalmente menor que a do óleo de macadâmia, evidenciando que os antioxidantes presentes no pistache devem ser mais resistentes à degradação em altas temperaturas.

Não foi encontrada na literatura nenhuma referência quanto à avaliação da estabilidade oxidativa do óleo de pistache. 
TABELA 6 - ESTABILIDADE OXIDATIVA DAS AMOSTRAS DE ÓLEO DE PISTACHE

\begin{tabular}{lccccc}
\hline Amostra & $\begin{array}{c}\text { Tempo de } \\
\text { armazenamento das } \\
\text { amêndoas (meses) }\end{array}$ & $\begin{array}{c}\text { Índice de } \\
\text { Peróxido } \\
\text { (meq/Kg) }\end{array}$ & \multicolumn{3}{c}{ Índice de Estabilidade Oxidativa (h) } \\
\cline { 5 - 6 } & inicial & nd & $688^{\circ} \mathrm{C}^{1}$ & $110^{\circ} \mathrm{C}^{2}$ & $120^{\circ} \mathrm{C}^{2}$ \\
\hline P 1 & 3 & 3,5 & 56,5 & nd & nd \\
P 1 & inicial & 0 & 93 & 34,2 & 14,2 \\
P 3 & & & & & 34,2 \\
\hline
\end{tabular}

P1 = óleo de pistache analisado no tempo 0 e após 3 meses de armazenamento.

P3 = óleo de amêndoas de pistache salgado.

1 fluxo de ar de $8,33 \mathrm{~L} / \mathrm{h}$.

2 fluxo de ar de10,0 L/h.

nd = não-determinado.

As amostras de óleo de pistache apresentaram baixos valores de índice de peróxidos (Tabela 6) e de acidez (Tabela 1) e elevado teor de matéria insaponificável (1,17 a 1,39\%), fração que contém os antioxidantes naturais do óleo.

A composição em ácidos graxos do óleo de pistache não é tão favorável quanto à resistência à oxidação em comparação ao óleo de macadâmia. O óleo de pistache apresentou até $32 \%$ de ácido linoléico (Tabela 2). Assim, a alta estabilidade oxidativa observada para o óleo de pistache poderia ser explicada pela presença de antioxidantes naturais na amêndoa. A eficiência do antioxidante é normalmente maior em temperatura mais baixa e os antioxidantes fenólicos em extratos naturais se decompõem em temperaturas mais elevadas, o que dificulta a comparação da estabilidade oxidativa entre óleos em diferentes temperaturas (FRANKEL, 1993).

\subsection{ESTABILIDADE OXIDATIVA DAS MISTURAS DOS ÓLEOS DE MACADÂMIA OU PISTACHE E SOJA E GIRASSOL}

Para a elaboração das misturas com os óleos comerciais de soja e girassol (nas concentrações de 5, 10 e 20\%) foram selecionadas as amostras de óleo de macadâmia crua e salgada (M1), crua e não-salgada (M4) e de óleo de pistache (P3).

A Tabela 7 apresenta a composição em ácidos graxos (\%) de óleos de soja, girassol, macadâmia e das misturas soja/macadâmia e girassol/macadâmia. Com a adição de óleos de macadâmia, os óleos compostos de soja apresentaram discreta diminuição nos teores de ácidos polinsaturados com redução de ácido linolênico de 5\% (presente no óleo de soja) para valores em torno de $4 \%$ e de linoléico de 54 para 44\% na mistura 80:20.

O teor de ácido linoléico do óleo de girassol (59\%) reduziu-se para 54\% na mistura 90:10 com óleo de macadâmia (M4).

As misturas de óleos de soja/pistache evidenciaram aumento no teor de C18:1 presente no óleo de soja (24\%) para 26 a 30\%. Houve redução no teor de C18:2 do óleo de soja (54\%) para 53 a 48\% nas misturas e, ainda, discreta redução no teor de C18:3 de 5\% para 4,8 a 3,9\% nas misturas (Tabela 8).

Verificou-se discreto aumento no teor de ácido oléico das misturas de óleo de girassol/pistache (P3) para 30 e 31,4\% em relação ao teor original no óleo de girassol (29\%). O ácido linoléico teve os seus valores ligeiramente reduzidos de $59 \%$ no óleo de girassol para 57,7 e 56,3\% nas misturas. Essas alterações na composição em ácidos graxos são favoráveis para aumentar a estabilidade oxidativa dos óleos.

As Tabelas 9 e 10 apresentam os resultados dos índices de estabilidade oxidativa e de peróxidos para os óleos de soja, girassol e respectivas misturas com os óleos de macadâmia e pistache. 
응

원

28

굴

出

品 里

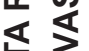

는

山

品

ज虫

过

$\varangle$

$\varangle$

世

品。

욤

这

이

吽

品

잉

일

o ?

\%

ํㅗㄴ

品 일

क 5

을

U⿺辶

$\sum \frac{1}{8}$

0 过

这

U

คิ

웅

ㄴ

U

10

ऽ

एँ

殅

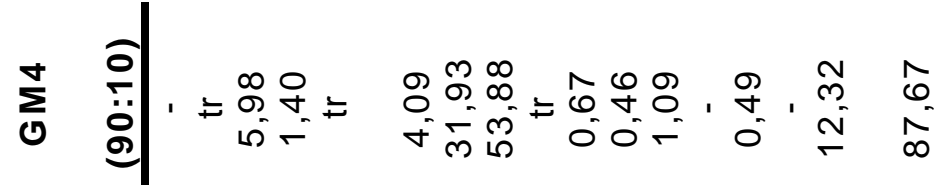

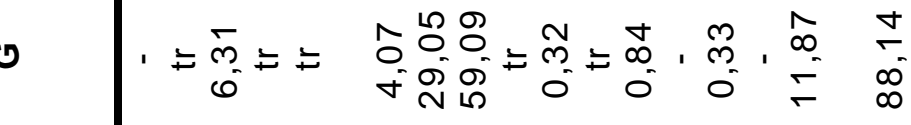

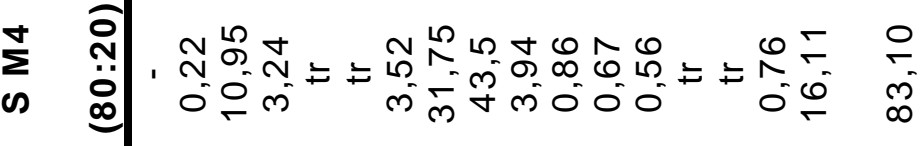

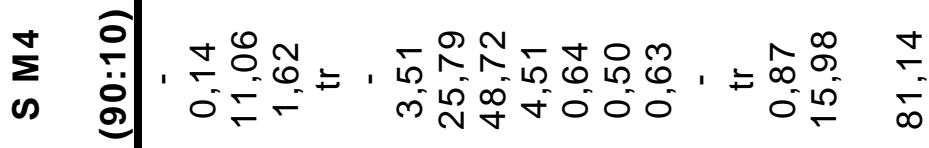

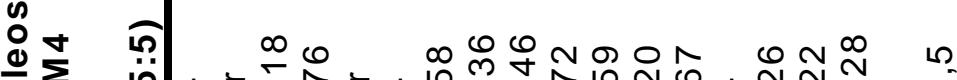

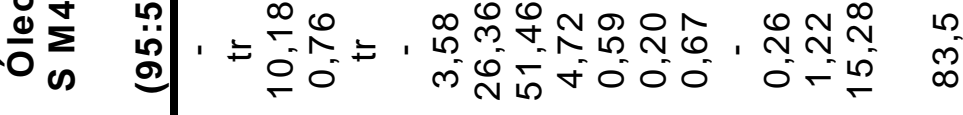

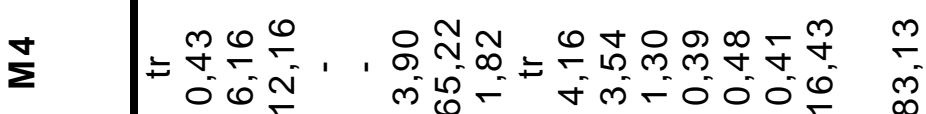

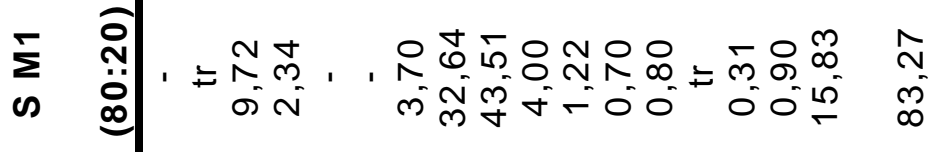

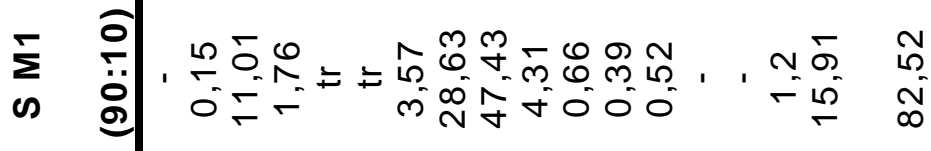

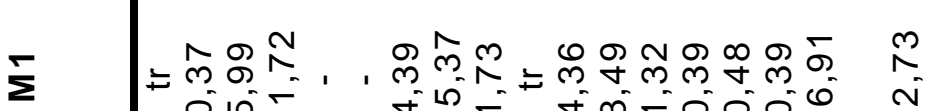

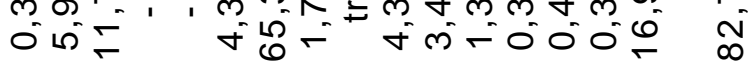

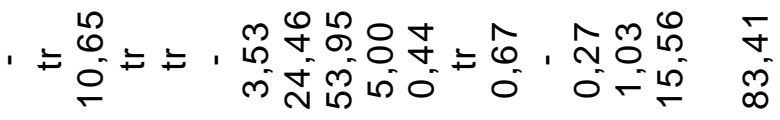

$$
\begin{aligned}
& \text { s }
\end{aligned}
$$

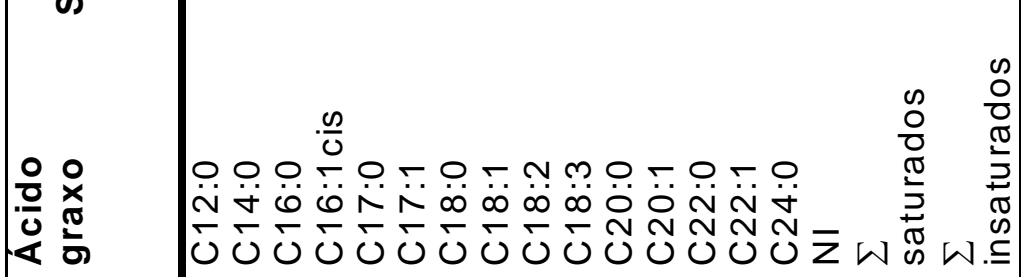

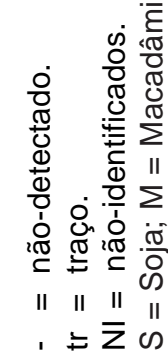


TABELA 8 - COMPOSIÇÃO EM ÁCIDOS GRAXOS (\%) POR CROMATOGRAFIA A GÁS DE ALTA RESOLUÇÃO DOS ÓLEOS DE SOJA, GIRASSOL, PISTACHE (P3) E SUAS RESPECTIVAS MISTURAS

\begin{tabular}{|c|c|c|c|c|c|c|c|c|}
\hline \multirow[t]{2}{*}{ Ácido graxo } & \multicolumn{8}{|c|}{ óleos } \\
\hline & $\mathbf{P}$ & $\mathbf{S}$ & $\begin{array}{c}\text { SP } \\
(95: 5)\end{array}$ & $\begin{array}{c}\text { SP } \\
(90: 10)\end{array}$ & $\begin{array}{c}\text { SP } \\
(80: 20)\end{array}$ & G & $\begin{array}{c}\text { GP } \\
(95: 5)\end{array}$ & $\begin{array}{c}\text { GP } \\
(90: 10)\end{array}$ \\
\hline C12:0 & $\operatorname{tr}$ & - & - & - & - & - & - & - \\
\hline C14:0 & $\operatorname{tr}$ & $\operatorname{tr}$ & $\operatorname{tr}$ & $\operatorname{tr}$ & 0,09 & $\operatorname{tr}$ & $\operatorname{tr}$ & $\operatorname{tr}$ \\
\hline C16:0 & 8,02 & 10,65 & 10,88 & 10,67 & 11,39 & 6,31 & 6,28 & 6,70 \\
\hline C16:1 & 0,75 & $\operatorname{tr}$ & tr & $\operatorname{tr}$ & 0,42 & $\operatorname{tr}$ & $\operatorname{tr}$ & $\operatorname{tr}$ \\
\hline C17:0 & - & $\operatorname{tr}$ & $\operatorname{tr}$ & $\operatorname{tr}$ & $\operatorname{tr}$ & $\operatorname{tr}$ & $\operatorname{tr}$ & $\operatorname{tr}$ \\
\hline C17:1 & - & - & - & - & $\operatorname{tr}$ & - & - & - \\
\hline C18:0 & 1,32 & 3,53 & 3,48 & 3,39 & 3,09 & 4,07 & 3,97 & 3,84 \\
\hline C18:1 & 56,85 & 24,46 & 26,22 & 27,68 & 30,37 & 29,05 & 30,08 & 31,41 \\
\hline C18:2 & 31,38 & 53,95 & 53,17 & 51,98 & 48,28 & 59,09 & 57,73 & 56,27 \\
\hline C18:3 & 0,55 & 5,00 & 4,78 & 4,57 & 3,93 & $\operatorname{tr}$ & 0,30 & 0,33 \\
\hline C20:0 & 0,20 & 0,44 & $\operatorname{tr}$ & $\operatorname{tr}$ & 0,33 & 0,32 & 0,40 & 0,32 \\
\hline C20:1 & 0,58 & $\operatorname{tr}$ & tr & 0,31 & 0,34 & $\mathrm{tr}$ & $\operatorname{tr}$ & $\operatorname{tr}$ \\
\hline C22:0 & 0,12 & 0,67 & 0,57 & 0,63 & 0,39 & 0,84 & 0,89 & 0,81 \\
\hline $\mathrm{C} 22: 1$ & tr & - & - & - & - & - & - & - \\
\hline C24:0 & $\operatorname{tr}$ & 0,27 & $\operatorname{tr}$ & $\operatorname{tr}$ & $\operatorname{tr}$ & 0,33 & 0,35 & 0,32 \\
\hline C24:1 & $\operatorname{tr}$ & 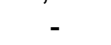 & & 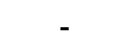 & - & - & - & - \\
\hline $\mathrm{NI}$ & 0,22 & 1,03 & 0,90 & 0,75 & 1,13 & - & - & - \\
\hline$\sum$ saturados & 9,66 & 15,56 & 14,93 & 14,69 & 15,29 & 11,87 & 11,89 & 11,99 \\
\hline$\sum$ insaturados & 90,11 & 83,41 & 84,17 & 84,54 & 83,34 & 88,14 & 88,11 & 88,01 \\
\hline
\end{tabular}

- = não-detectado.

$\operatorname{tr}=$ traços.

$\mathrm{P}=$ pistache; $\mathrm{G}=$ girassol; $\mathrm{S}=$ soja.

$\mathrm{NI}=$ Não-identificado.

TABELA 9 - ÍNDICES DE PERÓXIDO E DE ESTABILIDADE OXIDATIVA (OSI) DOS

ÓLEOS DE SOJA, GIRASSOL, MACADÂMIA (AMOSTRAS M1 E M4) E SUAS RESPECTIVAS MISTURAS

\begin{tabular}{|l|c|c|}
\hline Amostra & OSI $(\mathbf{h})^{{ }^{1}}$ & İndice de Peróxido (meq/kg) \\
\hline Oleo de soja ${ }^{*}$ & 14,4 & 1,17 \\
\hline Oleo de macadâmia M1 & $>96$ & 0 \\
\hline Soja/macadâmia M1 (90:10) & 15,8 & 1,66 \\
\hline Soja/macadâmia M1 (80:20) & 17,1 & 7,16 \\
\hline Oleo de macadâmia (M4) & 88,6 & 1,54 \\
\hline Soja/macadâmia M4 (95:5) & 15,4 & 1,18 \\
\hline Soja/macadâmia M4 (90:10) & 15,9 & 1,29 \\
\hline Soja/macadâmia M4 (80:20) & 17,6 & 0,82 \\
\hline Oleo de girassol & & 1,26 \\
\hline Girassol/macadâmia M4 (95:5) & 21,9 & 0,92 \\
\hline Girassol/macadâmia M4 (90:10) & 22,2 & 0,87 \\
\hline
\end{tabular}

* óleos com adição de antioxidantes pela própria indústria.

1 temperatura de $98^{\circ} \mathrm{C}$ e fluxo de ar de $8,33 \mathrm{~L} / \mathrm{h}$. 
TABELA 10 - ÍNDICES DE PERÓXIDO E DE ESTABILIDADE OXIDATIVA (OSI) DOS ÓLEOS DE SOJA, GIRASSOL, PISTACHE (P3) E SUAS MISTURAS

\begin{tabular}{lcc} 
Amostra & OSI (h) $\mathbf{~}^{\mathbf{1}}$ & $\begin{array}{c}\text { Índice de Peróxido } \\
\text { (meq/kg) }\end{array}$ \\
\hline Óleo de soja* & 14,4 & 1,17 \\
Óleo de pistache & 93 & 0 \\
Soja/pistache (95:5) & 15,6 & 0,77 \\
Soja:pistache (90:10) & 16,3 & 0 \\
Soja/pistache (80:20) & 19,3 & 0 \\
Óeo de girassol* & 21,9 & 1,26 \\
Girassol/pistache (95:5) & 22,6 & 1,27 \\
Girassol/pistache (90:10) & 23,1 & 1,30 \\
\hline
\end{tabular}

\footnotetext{
* óleos com adição de antioxidantes pela própria indústria.

1 temperatura de $98^{\circ} \mathrm{C}$ e fluxo de ar de $8,33 \mathrm{~L} / \mathrm{h}$.
}

Os óleos de macadâmia M1 e M4, utilizados nas misturas, apresentaram OSI maior que 96 e 88,6 horas, respectivamente (Tabela 9).

O óleo de macadâmia M4, adicionado ao óleo de soja nas concentrações de 5, 10 e 20\% elevou o OSI de 14,4 horas para 15,4; 15,9 e 17,6 horas, respectivamente (Tabela 9). Houve incremento do OSI das misturas em relação ao do óleo de soja de 7, 11 e 22\%, respectivamente.

Os óleos compostos de soja e de macadâmia M1 nas proporções 90:10 e 80:20 apresentaram OSI de 15,8 e 17,1 horas, respectivamente, evidenciando aumento de 10 e 19\% em relação ao OSI do óleo de soja (Tabela 9).

O óleo de pistache adicionado ao óleo de soja a 5, 10 e 20\% promoveu elevação do OSI de 14,4 horas para 15,6; 16,3 e 19,3 horas, respectivamente (Tabela 10), representando elevação de 9, 13 e 34\%, respectivamente, em relação ao OSI do óleo de soja.

A Figura 1 apresenta as curvas de condutividade elétrica ( $\mu \mathrm{S}$ ) versus tempo (Rancimat), obtidas para o óleo de soja e para as misturas com macadâmia e pistache na proporção (P3) 80:20. Observou-se que o aumento da estabilidade oxidativa foi mais pronunciado no óleo composto de soja/pistache em relação a mistura soja/macadâmia.

A adição de óleo de macadâmia M4 nas proporções de 5 e 10\% ao óleo de girassol elevou o OSI de 21,9 para 22,2 e 23 horas, respectivamente (Tabela 9). Para as misturas girassol/pistache nas proporções 95:5 e 90:10, o OSI foi de 22,6 e 23,1 horas, respectivamente, com acréscimo de 3 e 5\% em relação ao OSI do óleo de girassol (Tabela 10).

Em geral, o óleo de pistache apresentou desempenho semelhante ao obtido pelo óleo de macadâmia quando adicionados ao óleo de girassol.

Apesar da discreta elevação do OSI é possível obter aumento de estabilidade de óleos compostos, conforme observado por ANTONIASSI, PEÇANHA LAGO (1998) para o óleo de abacate que aumentou significativamente o OSI de 66 a 130\% (Rancimat $-110^{\circ} \mathrm{C}$ ), quando adicionado aos óleos de girassol e soja.

Os óleos de soja e girassol refinados apresentam teores variáveis de tocoferóis que dependem das condições de refino e da sua composição inicial. Os óleos refinados utilizados foram adicionados de ácido cítrico (seqüestrante de metais) e do antioxidante t - butil - hidroquinona (TBHQ) pela própria indústria. O sinergismo entre os antioxidantes dos óleos de soja e girassol e aqueles presentes nos óleos de macadâmia e pistache não proporcionou aumento significativo na estabilidade oxidativa dessas misturas. 

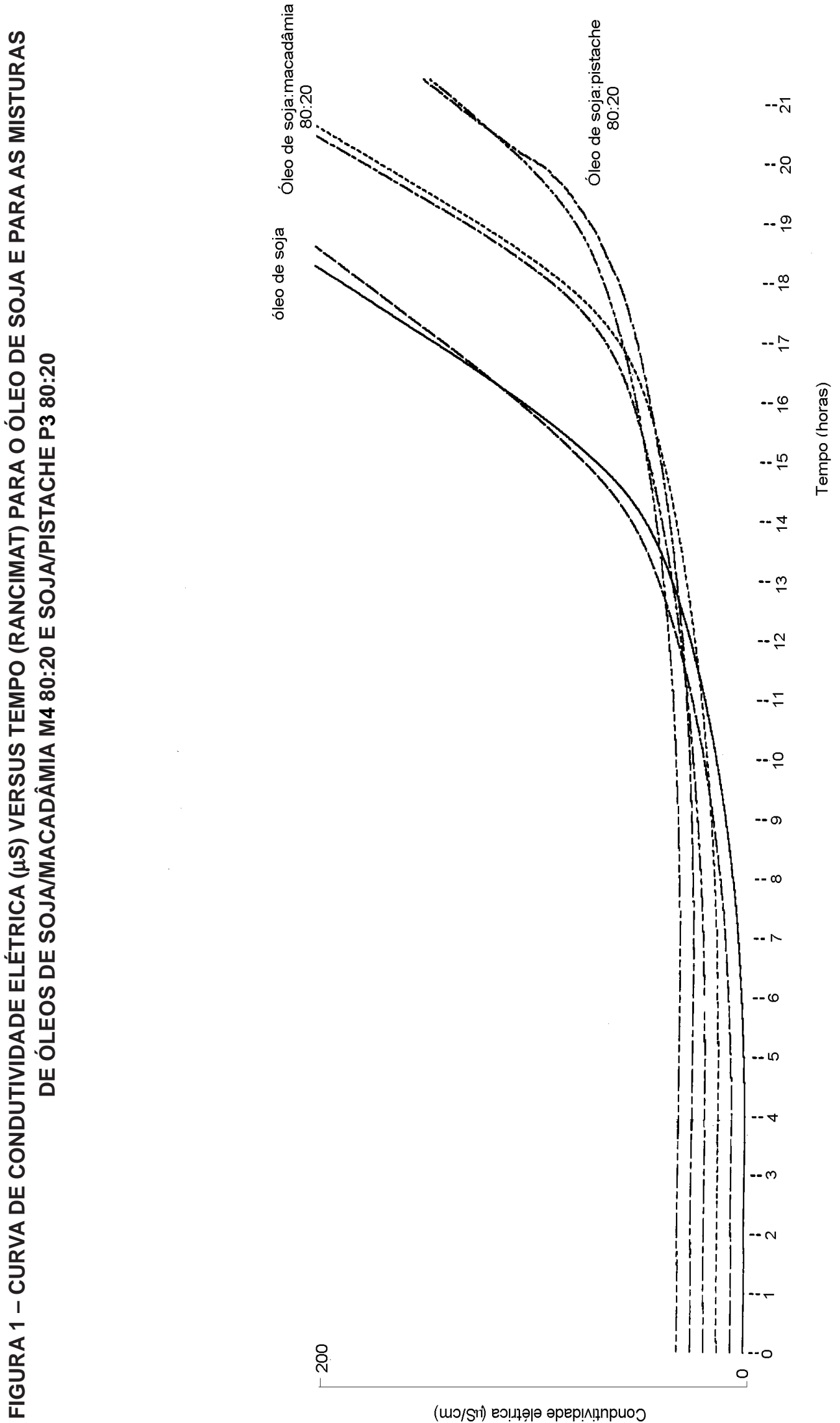

B.CEPPA, Curitiba, v. 25, n. 1, jan./jun. 2007 


\section{CONCLUSÃO}

Os óleos de macadâmia e pistache apresentaram valores de índice de estabilidade oxidativa superiores aos relatados pela literatura para os óleos vegetais.

Constatou-se redução da estabilidade do óleo com o tempo de armazenamento, tanto do óleo quanto das amêndoas, mesmo em temperatura de congelamento.

A redução do índice de estabilidade oxidativa com a temperatura de análise mostrou-se proporcionalmente menor para o óleo de pistache em relação ao óleo de macadâmia, indicando que os antioxidantes presentes no óleo de pistache apresentam maior resistência à degradação pela temperatura.

A adição de óleos de macadâmia e de pistache aos óleos de soja e girassol proporcionaram elevação discreta no índice de estabilidade oxidativa das misturas.

\section{ABSTRACT}

\section{OXIDATIVE STABILITY OF MACADAMIA AND PISTACHIO OILS}

The objective of this work was to evaluate the composition and oxidative stability of macadamia and pistachio oils. Oils from macadamia and pistachio nuts were analyzed for their composition in fatty acids, triacylglycerols and sterols. The Oxidative Stability Index (OSI) of this oils was measured using a Rancimat $679 \mathrm{Metrohm}$ at 98,110 and $120^{\circ} \mathrm{C}$ with air flow of 8.33 and $10.0 \mathrm{~L} / \mathrm{h}$. Macadamia and pistachio oils were also added to soybean and sunflower oils (in levels of 5 to $20 \%$ ) to evaluate a possible oxidative stability increase of the latter. Oil samples of macadamia nuts showed as predominance fatty acids, the oleic acid (63.41 to $67.30 \%)$ and palmitoleic acid (10.32 to $14.27 \%$ ) however the major fatty acids in pistachio nut oil samples were oleic $(53.83 \%$ to $56.85 \%)$ and linoleic $(31.38 \%$ to $32.26 \%)$ acids. The OSI at $98^{\circ} \mathrm{C}$ for macadamia nut oil and for pistachio nut oil reached respectively, $93 \mathrm{~h}$ and higler than $96 \mathrm{~h}$, indicating high oxidative stability. Such values are between the highest found in the literature for vegetable oils in this temperature. A reduction of the OSI occurred when the temperature increased, for both oils. There was only a slight increase in the blends of macadamia and pistachio oils and sunflower and soybean oils.

KEY-WORDS: MACADAMIA; PISTACHIO; OIL; OSI (OIL STABILITY INDEX); RANCIMAT.

\section{REFERÊNCIAS}

1 ALLMAN-FARINELLI, M.A.; GOMES, K.; FAVALORO, E.J.; PETOCZ, P. A diet rich in high-oleic-acid sunflower oil favorably alters low-density lipoprotein cholesterol, triglycerides, and factor VII coagulant activity. Journal of the American Dietetic Association, v.105, n.7, p.1071-1079, 2005.

2 ANTONIASSI, R. Métodos de avaliação da estabilidade oxidativa de óleos e gorduras. Boletim do CEPPA, Curitiba, v.19, n.2, p.353-380, jul.dez. 2001.

3 ANTONIASSI, R.; PEÇANHA, B.R.B.; LAGO, R.C.A. Efeito da adição de óleo de abacate na estabilidade oxidativa de óleos de soja e girassol. In: CONGRESSO BRASILEIRO DE CIÊNCIA E TECNOLOGIA DE ALIMENTOS, 16., Rio de Janeiro, 1998, Anais... Rio de Janeiro: SBCTA, 1998 p.1208-1211.

4 AOCS. American Oil Chemists' Society. Official methods and recommended practices of the American Oil Chemists' Society. Champaign, IL., 1997.

5 ASLAN, M.; ORHAN, I.; SENER, B. Comparison of the seed oils of Pistacia vera L. of different origins with respect to fatty acids. International Journal of Food Science \& Technology, v.37, n.3, p. 333-335, 2002.

6 BINKOSKI, A.E.; KRIS-ETHERTON, P.M.; WILSON, T.A.; MOUNTAIN, M.L.; NICOLOSI, R.J. Balance of unsaturated fatty acids is important to a cholesterol-lowering diet: comparison of mid-oleic sunflower oil and olive oil on cardiovascular disease risk factors. Journal of the American Dietetic Association, v.105, n.7, p.1080-1087, 2005.

7 CODEX ALIMENTARIUS. Fats, Oils and related products. $2^{\text {nd }}$ ed. Roma, 2001. v. 8.

8 DANECHRAD, A. Study of pistachio oil (Pistacia vera L.). Oleagineux, v. 29, n. 3, p. 153-154, 1974. 
9 FAO. Food and Agriculture Organization of the United Nations. Production ProdSTAT: crops. on-line. Disponível em: <http://faostat.fao.org> Acesso em: 15 mar. 2007.

10 FRANKEL, E.N. In search of better methods to evaluate natural antioxidants and oxidative stability in food lipids. Trends in Food Science \& Technology, v.4, n.7, p. 220-225, 1993.

11 GARG, M.L.; BLAKE, R.J.; WILLS, R.B.H. Macadamia nut consumption lowers plasma total and LDL cholesterol levels in hypercholesterolemic men. Journal of Nutrition, v.133, n.4, p.1060-1063, 2003.

12 GUNSTONE, F.D.; HARWOOD, J.L.; PADLEY, F.B. The Lipid Handbook. $2^{\text {nd }}$ ed. London: Chapman \& Hall, 1994. $551 \mathrm{p}$.

13 HARTMAN, L; LAGO, R.C.A. A rapid preparation of fatty acid methyl esters from lipids. Laboratory Practice, London, v.22, n.8, p.475-476, 1973.

14 HILL, S.E. A comparison of modern instruments for the analysis of the oxidation stability of fats, oils and foods. Inform, v.5, n.1, p.104-109, 1994.

15 HOLCAPEK, M.; JANDERA, P.; ZDERADICKA, P.; HRUBA, L. Characterization of triacylglycerol and diacylglycerol composition of plant oils using high-performance liquid chromatography-atmospheric pressure chemical ionization mass spectrometry. Journal of Chromatography A, v.1010, n.2, p.195-215, 2003.

16 IUPAC. International Union of Pure and Applied Chemistry. Standard methods for the analysis of oils, fats and derivatives. $7^{\text {th }}$ ed. Oxford: Blackwell Sci., 1992.

17 KAIJSER, A.; DUTTA, P.; SAVAGE, G. Oxidative stability and lipid composition of macadamia nuts grown in New Zealand. Food Chemistry, v.71, n.1, p.67-70, 2000.

18 LÄUBLI, M. W.; BRUTTEL, P. A. Determination of the oxidative stability of fats and oils: comparison between the active oxygen method (AOCS Cd 12-57) and the Rancimat method. Journal of the American Oil Chemists' Society, Champaign, v.63, n.6, p.792-795, 1986.

19 LERCKER, G.; FREGA, N.; BOCCI, F.; BERTACCO, G. Milk fat. Gas chromatographic analysis of triglycerides in assessment of authenticity of butter. Scienza eTecnica Lattiero Casearia, v.43, n.2, p. 95-110, 1992.

20 LOZANO, Y. F.; DHUIQUE MAYER, C.; BANNON, C.; GAYDOU, E. M. Unsaponifiable matter, total sterol and tocopherol contents of avocado oil varieties. Journal of the American Oil Chemists' Society, Champaign, v.70, n.6, p.561-565, 1993.

21 MacFARLANE, N.; HARRIS, V. Extraction of macadamia oil using a small expeller. Tropical Science, v.23, n.3, p.205-214, 1981.

22 MAGUIRE, L.S.; O'SULLIVAN, M.; GALVIN, K.; O'CONNOR, T.P.; O'BRIEN, N.M. Fatty acid profile, tocopherol, squalene and phytosterol content of walnuts, almonds, peanuts, hazelnuts and the macadamia nut. International Journal of Food Sciences and Nutrition, v.55, n.3, p.171-178, 2004.

23 MARRocos, P. C. L.; ANDERSEN, O.; BRUCKNER, C. H.; MIRANDA, L. C. G. de ; CARDOSO, A. A.; BARRETO, M. Composição química das amêndoas de quatro cultivares de Macadamia integrifolia Maiden e Betche. Agrotópica, llhéus v.8, n.3, p.61-64, 1996.

24 MASON, R. L.; McCONACHIE, J. A hard nut to crack. Food Australia, v.46, n.10, p.466-471, 1994.

25 MUKUDDEM-PETERSEN, J.; OOSTHUIZEN, W.; JERLING, J.C. A Systematic review of the effects of nuts on blood lipid profiles in humans. Journal of Nutrition, v.135, n.9, p.2082-2089, 2005.

26 OLIVEIRA, A.J.; GUTIERREZ, L.E.; OLIVEIRA, G.D.; CANTARELLI, P.R. Características químicas e composição do óleo da torta da semente de nogueira macadâmia. Boletim da Sociedade Brasileira de Ciência e Tecnologia de Alimentos, n.52, p.1-104, 1980.

27 PAULINO, F.D.G.; MARCHINI, L.C. Insetos associados às panículas de macadâmia (Macadamia integrifolia, Maiden \& Betche). Scientia agricola, v.55, n.3, p.528-533, 1998.

28 QUINN, L. A.; TANG, H. H. Antioxidant properties of phenolic compounds in macadamia nuts. Journal of the American Oil Chemists' Society, Champaign, v.73, n.11, p.1585-1588, 1996. 
29 ROSALES, G. Determinación de la estabilidad oxidativa de aceite de oliva vírgenes: comparación entre el método del oxígeno activo (A.O.M.) y el método Rancimat. Grasas y Aceites, v. 40, n.1, p.1-5, 1989.

30 SACRAMENTO, C.K.; PEREIRA, F.M. Fenologia da floração da nogueira macadâmia (Macadamia integrifolia Maiden \& Betche) nas condições climáticas de Jaboticabal, São Paulo, Brasil. R. Bras. Frutic., v.25, n.1, p.19-22, 2003.

31 USDA. United States Department of Agriculture - Foreign Agricultural Service. Macadamia situation \& outlook in selected countries production [on line]. Disponível em: <http://www.fas.usda.gov>htp/ Hort_Circular/2004/04-02-04\%20Web\%20Art/2004\%20Macadamia\%20Situation\%20and\%20 Outlook\%20in\%20Selected\%20Countries.pdf>. Acesso em: 15 mar. 2007.

32 YILDIZ, M.; GURCAN, S.T.; OZDEMIR, M. Oil composition of pistachio nuts (Pistachia vera L.) from Turkey. Fette/Lipid, v.100, n.3, p.84-86, 1998. 